\title{
Fasting Insulin Pulsatile Secretion in Lean Women with Polycystic Ovary Syndrome
}

\author{
T. GRIMMICHOVÁ ${ }^{1}$, J. VRBÍKOVÁ ${ }^{1}$, P. MATUCHA ${ }^{1}$, K. VONDRA ${ }^{1}$, P. P. VELDHUIS ${ }^{2}$, \\ M. L. JOHNSON ${ }^{2}$
}

${ }^{1}$ Institute of Endocrinology, Prague, Czech Republic, ${ }^{2}$ Department of Pharmacology, University of Virginia, Charlottesville, Virginia, USA

Received November 12, 2007

Accepted January 17, 2008

On-line February 13, 2008

\begin{abstract}
Summary
The aim of our study was to evaluate rapid insulin pulses and insulin secretion regularity in fasting state in lean women with polycystic ovary syndrome (PCOS) in comparison to lean healthy women. PCOS $(n=8)$ and controls $(n=7)$ underwent every minute blood sampling for $60 \mathrm{~min}$. Insulin pulsatility was assessed by deconvolution and insulin secretion regularity by approximate entropy methodology. PCOS had higher testosterone $(p<0.02)$, prolactin $(p<0.05)$ and lower sex hormone binding globulin (SHBG) $(p<0.0006)$ levels than controls. Approximate entropy, insulin pulse frequency, mass, amplitude and interpulse interval did not differ between PCOS and controls. PCOS had broader insulin peaks determined by a common half-duration $(p<0.07)$. Burst mass correlated positively with testosterone $(p<0.05)$ and negatively with SHBG $(p<0.0004)$ and common half-duration correlated positively with prolactin $(p<0.008)$ and cortisol levels $(p<0.03)$. Approximate entropy positively correlated with BMI $(p<0.04)$ and prolactin $(p<0.03)$. Lean PCOS patients tended to have broader insulin peaks in comparison to healthy controls. Prolactin, androgens and cortisol might participate in alteration of insulin secretion in PCOS-affected women. Body weight and prolactin levels could influence insulin secretion regularity.
\end{abstract}

\section{Key words}

Insulin • Pulse • Polycystic ovary syndrome • Diabetes mellitus

\section{Corresponding author}

Tereza Grimmichová, Institute of Endocrinology, Národní 8, 11694 Prague 1, Czech Republic. E-mail: tgrimmichova@endo.cz

\section{Introduction}

Insulin is physiologically secreted in a pulsatile manner with a variable basal insulin release. The contribution of pulsatile insulin secretion to total insulin secretion has been estimated as being at least $70 \%$, both in fasting and in postabsortive states (Porksen et al. 1995, Porksen 2002).

Insulin pulsatility is composed of rapid regular pulses of 5 to $15 \mathrm{~min}$ in frequency, superimposed on ultradian (slow) oscillations with a period of 80-150 min. It has been assumed that rapid insulin pulses suppress hepatic gluconeogenesis and slow insulin pulses contribute to glucose utilization in the peripheral tissues (Porksen 2002). Glucose is the most important regulator of insulin secretion, with a feedback loop between slow pulses and blood glucose levels. Rapid insulin pulses, in addition to being driven by glycaemic oscillations, are controlled by the hypothetical intrapancreatic neuronal pacemaker arising from rich pancreatic innervation. Many other metabolic substrates, hormones or neurotransmitters also influence insulin secretion (Stagner et al. 1980, Ahren 2000, Porksen et al. 2000).

Polycystic ovary syndrome is one of the most common endocrinopathies of women in their fertile years. Together with the reproductive abnormalities of chronic anovulation and hyperandrogenism, hyperinsulinaemia and insulin resistance (IR) are present in a relevant number of women affected with PCOS. The incidence of impaired glucose tolerance (IGT) and diabetes mellitus type 2 (DM 2) is significantly increased in PCOS in comparison with healthy control subjects (Ehrmann et al. 1999, Legro et al. 1999).

Besides insulin resistance, insulin secretory dysfunction is another risk factor for DM 2. The alterations in insulin pulsatile secretion and insulin 
release orderliness might be an early marker of beta-cell dysfunction. Abnormal insulin pulsatile patterns were detected even in first degree relatives of patiens with DM 2 , who still had normal first phase secretory response to glucose (O'Rahilly et al. 1988). Insulin secretion in PCOS was studied in a limited number of studies (Dunaif et al. 1996, Ehrmann et al. 1995, Holte et al. 1994, Vrbíková et al. 2007) and the data about insulin pulsatile release in PCOS is especially sparse (Armstrong et al. 2001). Concerning slow insulin pulses, others described significantly higher basal insulin secretory rates and attenuated secretory responses to meals in obese women with PCOS (O'Meara et al. 1993).

The aim of our study was to evaluate the rapid insulin pulses and the regularity of insulin secretion in lean women affected with PCOS in comparison to healthy lean women.

\section{Methods}

After an overnight fast, the participants were brought to the Clinical Research Unit in Institute of Endocrinology. The protocol was approved by the Instutional Ethical Committe. Before entering the study, written informed consent was obtained after written and oral information. The study group consisted of 8 women affected with PCOS fulfilling the diagnostic criteria by using definition ESHRE/ASRM (2004). The diagnosis of PCOS is accepted, when 2 out of 3 from: oligo/amenorhoea, hyperandrogenaemia and or clinical manifestation of either acne or hirsutismus and ultrasonographic morphology of polycystic ovary are present. The control group (C) consisted of 7 healthy women with regular menstrual cycles and no clinical or biochemical signs of hyperandrogenemia. Pelvic ultrasonography was not performed in healthy controls. Both groups were without medication affecting carbohydrate metabolism including oral contraceptives at least for the preceding 3 months and without family history of diabetes mellitus. Impaired glucose tolerance, diabetes mellitus, thyroid dysfunction, hyperprolactinemia, hypercortisolism and the late onset congenital adrenal hyperplasia were all excluded using the appropriate biochemical parameters or tests.

Basal blood samples for the determination of testosterone, androstenedione, dehydroepiandrosterone sulfate (DHEAS), lutropin (LH), follitropin (FSH), progesterone, estradiole, 17-hydroxyprogesterone (17OHP) were taken in the fasting state in the early follicular phase of the menstrual cycle (between 1 st and 5th day at, 7-8.30 a.m.) or in the case of secondary amenorhoea at any time. After the cannulae were placed in an antecubital vein for sampling purposes, the women affected with PCOS and control women underwent frequent blood sampling in 1-minute intervals for $60 \mathrm{~min}$. Blood (cca $2 \mathrm{ml}$ ) was collected from $5 \mathrm{~s}$ before to $5 \mathrm{~s}$ after each minute. After finishing each blood sampling $0.6 \mathrm{ml}$ of saline solution was administered to dead space. Ten seconds before sampling, the saline solution from the dead space was withdrawn and discarded. Serum insulin concentration was estimated each minute. The samples were analyzed the same day as the study was performed. The resultant insulin concentration time series was analyzed by deconvolution analysis. Insulin secretion regularity was estimated by approximate entropy. Both analyses are described below.

Quantitative insulin sensitivity check index (QUICKI) was calculated as $1 /\left(\log \left(\mathrm{G}_{0}\right)+\log \left(\mathrm{I}_{0}\right)\right)$ where $\mathrm{G}_{0}$ is fasting plasma glucose (milligrams per deciliter), and $\mathrm{I}_{0}$ is fasting plasma insulin (microunits per milliliter) (Katz et al. 2000).

Serum glucose concentrations were measured using the glucose-hexokinase method (Integra 400 plus, Roche Diagnostics GmbH, Mannheim, Germany). Serum insulin was determined in singlet by ELISA (Roche Diagnostics GmbH, Mannheim, Germany) using two monoclonal murine antibodies. Intrassay $\mathrm{CV} 1.5 \%$ and interassay $\mathrm{CV} 4.9 \%$ are for insulin detection range of $5.93 \pm 0.09 \mu \mathrm{U} / \mathrm{ml}$. The higher insulin detection range is $14.5 \pm 0.13 \mu \mathrm{U} / \mathrm{ml}$ with intrassay CV $0.9 \%$ and interassay CV $3.7 \%$. Minimal detection concentration is $0.20 \mu \mathrm{U} / \mathrm{ml}$. The assay has no cross-reactivity with proinsulin. Cpeptide was measured by the electrochemiluminescence immunoassay ECLIA (Modular E170, Roche Diagnostics $\mathrm{GmbH}$, Mannheim, Germany). The cross-reactivity of antiserum with both insulin and glucagon is less than 0.05 $\%$ with intra-and inter-assay $\mathrm{CV}$ of $0.5 \%$ and $1.6 \%$, respectively. Testosterone was determined by standard RIA using anti-testosterone-3-carboxymethyloxime: bovine serum albumin (BSA) antiserum and testosterone 3carboxymethyloxime-tyrosylmethylester- $\left({ }^{125} \mathrm{I}\right)$ as a tracer; the intra-assay and inter-assay coefficients of variation $(\mathrm{CV}$ values) were $10.2 \%$ and $10 \%$ respectively, and the sensitivity is $0.21 \mathrm{nmol} / 1$ (normal range $0.4-3.0 \mathrm{nmol} / \mathrm{l}$ ). Prolactin was measured in serum by chemiluminescence immunoanalysis ECLIA (Elecsys Prolactin II, Roche, Germany) (normal range 6-29.9 ng/ml). Androstenedione was determined using a standard RIA with anti- 
androstenedione-6-carboxymethyloxime: BSA antiserum and $\left({ }^{3} \mathrm{H}\right)$ androstenedione as a tracer. The intra-assay and inter-assay $\mathrm{CV}$ values were $10 \%$ and $10.2 \%$ respectively and the sensitivity was $0.39 \mathrm{nmol} / \mathrm{l}$. Sex hormone binding globulin (SHBG) was estimated using IRMA method (Orion, Espoo, Finland) with an intra-assay CV of $6.1 \%$ and an inter-assay $\mathrm{CV}$ of $7.9 \%$ (normal range 43.2-94.8 nmol/l). DHEAS (normal range 2.4-14.5 umol/1; intraassay CV of $3.5 \%$ and inter-assay CV of $10.2 \%$ ), 17-OHP (normal range 1.1-8.4 nmol/1; intra-assay $\mathrm{CV}$ of $5.2 \%$ and inter-assay $\mathrm{CV}$ of $6.5 \%$ ) and estradiol (normal range 0.11 $1.29 \mathrm{nmol} / \mathrm{l}$; intra-assay CV of $4.4 \%$ and inter-assay $\mathrm{CV}$ of $4.6 \%$ ) were measured by the RIA kit from Immunotech (Prague, Czech Republic). LH was determined by IRMA (Immunotech, Prague, Czech Republic) with an intra-assay $\mathrm{CV}$ of $3.7 \%$ and an inter-assay $\mathrm{CV}$ of $4.3 \%$. FSH was estimated by IRMA (Immunotech, Prague, Czech Republic) with an intra-assay CV of $2.6 \%$ and an interassay CV of $4.5 \%$. Total cholesterol, high-density lipoprotein (HDL)-cholesterol and triglycerides were measured by photometry (Ecoline 25, Vitalab Elipse; Merck; Darmstadt; Germany) with intra-assay CVs 1.6\%, $1.7 \%$ and $1.2 \%$ and inter-assay CVs of $1.9 \%, 2.1 \%$ and $1.9 \%$, respectively.

\section{Deconvolution analysis of the data}

Deconvolution analysis was developed for endocrinological purposes as a mathematical procedure for measuring simultaneously hormone secretion and elimination. Insulin concentration time series were analyzed by deconvolution method to detect and quantify insulin secretory pulses. We employed several different deconvolution algorithms Pulse 2, Pulse 4 and AutoDecon. The principle of deconvolution software was described previously (Veldhuis and Johnson 1992, Veldhuis and Johnson 1994). Briefly, the deconvolution method is a multiparameter technique validated previously and correctly identifying more than $90 \%$ of hormone pulses (sensitivity) as correctly recognizing their absence (Johnson et al. 2004). The insulin concentrations were assumed to result from five determinable and correlated parameters: 1) a finite number of separate insulin pulses occurring at specific times, 2) individual amplitudes, 3) a common half-duration (duration of an algebraically Gaussian secretory pulse at half-maximal amplitude), 4) basal time invariant insulin secretion and 5) monoexponential or biexponential insulin model of elimination in the systemic circulation. Biexponential model of insulin clearance was estimated with rapid (first)
$2.8 \mathrm{~min}$ and slow (second) $5.0 \mathrm{~min}$ half-lives with fractional slow compartment of 0.28 . We calculated monoexponencial insulin half-life of 3.3 (2.8-4.1) $\mathrm{min}$ in PCOS and 3.2 (2.6-4.1) min in healthy controls.

We used the root mean square of residuals (RMS) and residual variance (\%) to assess optimal insulin kinetics parameters (best fit curve). We derived the best fit curve with following RMS and residual variance in PCOS and healthy women $(0.77 \pm 0.23$ vs $0.9 \pm 0.26 \mathrm{mUI} / \mathrm{l} ; 9.44 \pm 4.73$ vs $9.14 \pm 8.79 \%$, respectively).

The following parameters were calculated: secretory pulse number (the number of significant secretory pulses per $60 \mathrm{~min}$ ), interpulse interval (time in minutes separating successive pulses), pulse mass (the mass of the calculated secretory pulses) (mUI/l), amplitude (maximal secretory rate within a pulse) (mUI/l/min), $\mathrm{AUC}_{0-60}$ (area under the curve, overall insulin secretion per $60 \mathrm{~min})(\mathrm{mUI} / \mathrm{l})$, common half-duration $(\mathrm{mUI} / \mathrm{min})$ and basal secretion (mUI/l/min).

Approximate entropy (ApEn) is used as a modelindependent and scale-invariant statistic. In brief, ApEn assumes the orderliness of hormonal release patterns. ApEn is computed as the sum of the negative logarithms of the conditional probabilities that subpatterns of length $\mathrm{m}$ in a time series recur upon next $(\mathrm{m}+1)$ incremental comparison within a given tolerance range $\mathrm{r}$. We used $\mathrm{m}=$ 1 and $\mathrm{r}=20 \%$ of the intraseries SD, which provides a normalized (scale-independent) ApEn statistics. ApEn was in detail described previously (Pincus et al. 1999) .

\section{Statistics}

All data are given as retransformed means with a $95 \%$ confidence interval. Unpaired t-tests and Pearson correlation coefficients were used on transformed data to evaluate differences between groups and the mutual relationship among the variables, respectively $(p<0.05)$ was considered statistically significant. RMS and residual variance are given as means $\pm \mathrm{SD}$.

\section{Results}

The clinical, basal biochemical and hormonal parameters of women affected with PCOS and healthy subjects are given in Table 1. PCOS women had significantly higher testosterone $(\mathrm{p}<0.02)$, prolactin $(\mathrm{p}<0.05), \quad 17-\mathrm{OHP} \quad(\mathrm{p}<0.03)$ and estradiol $(\mathrm{p}<0.05)$ concentrations and lower SHBG levels $(p<0.0006)$. We did not observe significant diference between groups in basal insulinaemia, basal glucose levels, C-peptide and QUICKI. 
Table 1. Clinical, hormonal and biochemical parameters of PCOS subjects $(n=8)$ and controls $(n=7)$

\begin{tabular}{|c|c|c|c|c|c|c|c|}
\hline & & PCO & & & Contr & & \\
\hline & & & CI & & CI & CI & \\
\hline & & Lower & Upper & & Lower & Upper & \\
\hline & Mean & limit & limit & Mean & limit & limit & $\mathbf{p}<$ \\
\hline$B M I\left(\mathrm{~kg} / \mathrm{m}^{2}\right)$ & 21.9 & 20.2 & 23.5 & 20.1 & 18.9 & 21.2 & NS \\
\hline Age (years) & 25.1 & 21.8 & 29.5 & 30.2 & 25.1 & 38.1 & NS \\
\hline Insulinaemia basal (mUI/l) & 5.1 & 3.9 & 6.5 & 4.2 & 3.1 & 5.6 & NS \\
\hline Blood glucose basal (mmol/l) & 4.17 & 4 & 4.35 & 4.12 & 4 & 4.4 & NS \\
\hline C-peptide (nmol/l) & 0.54 & 0.4 & 0.71 & 0.51 & 0.23 & 0.96 & NS \\
\hline QUICKI & 0.39 & 0.37 & 0.4 & 0.4 & 0.38 & 0.43 & NS \\
\hline Total cholesterol $(\mathrm{mmol} / \mathrm{l})$ & 4 & 3.7 & 4.8 & 4 & 3.6 & 4.7 & NS \\
\hline HDL cholesterol (mmol/l) & 1.6 & 1.2 & 1.8 & 1.8 & 1.6 & 1.9 & NS \\
\hline Triglycerides (mmol/l) & 0.75 & 0.6 & 0.9 & 0.7 & 0.4 & 0.9 & NS \\
\hline Testosterone (nmol/l) & 3.2 & 2.8 & 3.6 & 2.3 & 0 & 3.3 & 0.02 \\
\hline DHEAS (mmol/l) & 7.1 & 5.6 & 8.3 & 5.5 & 0 & 8.1 & NS \\
\hline Androstenedione (nmol/l) & 8.6 & 5.9 & 12.9 & 7.4 & 5 & 11.4 & NS \\
\hline SHBG (nmol/l) & 46.3 & 28.4 & 64.1 & 98.1 & 83.1 & 113.1 & 0.0006 \\
\hline Prolactin (ng/ml) & 23.8 & 16.8 & 32.5 & 13.7 & 6.3 & 25.4 & 0.05 \\
\hline Estradiol (nmol/l) & 0.12 & 0.1 & 0.14 & 0.09 & 0.05 & 0.13 & 0.05 \\
\hline Progesterone (nmol/l) & 2.5 & 1.4 & 3.6 & 2.8 & 0 & 7.4 & NS \\
\hline$L H(I U / l)$ & 4.5 & 2.8 & 8.4 & 6.5 & 3.1 & 20.4 & NS \\
\hline FSH (IU/l) & 6.3 & 5.25 & 7.8 & 8 & 6.4 & 10.4 & NS \\
\hline Cortisol (nmol/l) & 564 & 442 & 729 & 448.7 & 306 & 680 & NS \\
\hline 17-hydroxyprogesterone (nmol/l) & 2.5 & 1.8 & 3.7 & 1.4 & 0.9 & 2.2 & 0.03 \\
\hline
\end{tabular}

Values are given as means and $95 \%$ confidence interval (CI); p - value-statistical significance; NS - not significant; QUICKI Quantitative insulin sensitivity check index; LH - luteinising hormone; FSH - follicle stimulating hormone; DHEAS dehydroepiandrosterone sulfate; BMI - body mass index; SHBG - sex hormone binding globulin

Table 2. Deconvolution analysis results of rapid insulin pulsatile secretion in PCOS $(n=8)$ and controls $(n=7)$

\begin{tabular}{|c|c|c|c|c|c|c|c|}
\hline & & PCOS & & & Controls & & \\
\hline & Mean & $\begin{array}{l}\text { CI } \\
\text { Lower } \\
\text { limit }\end{array}$ & $\begin{array}{l}\text { CI } \\
\text { Upper } \\
\text { limit }\end{array}$ & Mean & $\begin{array}{l}\text { CI } \\
\text { Lower } \\
\text { limit }\end{array}$ & $\begin{array}{l}\text { CI } \\
\text { Upper } \\
\text { limit }\end{array}$ & $\mathbf{p}<$ \\
\hline Number of peaks per 1 hour & 9.7 & 7.7 & 11.7 & 9.9 & 7.2 & 12.55 & NS \\
\hline Basal secretion (mUI/l/min) & 0.7 & 0.4 & 0.98 & 0.5 & 0.24 & 0.82 & NS \\
\hline Half-life of insulin (min) & 3.3 & 2.8 & 4.1 & 3.2 & 2.6 & 4.1 & NS \\
\hline$A U C_{O-60}(m U I / l)$ & 300.5 & 235.6 & 398.2 & 255.3 & 188.2 & 340.2 & NS \\
\hline Common half-duration (mUI/min) & 1.97 & 1.1 & 3.37 & 0.89 & 0.51 & 1.49 & 0.07 \\
\hline Secretory pulse amplitude (mUI/l/min) & 1.1 & 0.7 & 2.1 & 1.5 & 1 & 2.6 & NS \\
\hline Secretory pulse mass (mUI/l) & 2.1 & 1.55 & 3 & 1.4 & 0.96 & 2.4 & NS \\
\hline Interpulse interval (min) & 5.87 & 5 & 7.2 & 5.56 & 4.6 & 7.1 & NS \\
\hline Approximate entropy & 1.14 & 1.09 & 1.19 & 1.08 & 0.94 & 1.16 & NS \\
\hline
\end{tabular}

Values are given as means and $95 \%$ confidence interval (CI); NS-not significant; $\mathrm{AUC}_{0-60}$ - area under the curve, overall insulin secretion during 1 hour; $p$-value-statistical significance 
Table 3. Correlations in PCOS subjects $(n=8)$ and controls $(n=7)$

\begin{tabular}{|c|c|c|c|c|c|c|c|c|c|c|c|c|}
\hline & 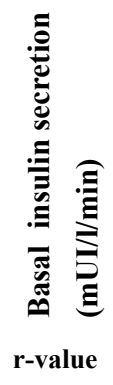 & $\mathbf{p}<$ & 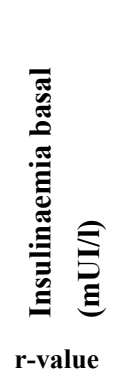 & $\mathbf{p}<$ & 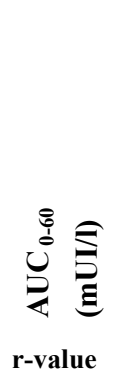 & $\mathbf{p}<$ & $\frac{\sqrt[1]{1}}{2}$ & $\mathbf{p}<$ & r-value & $\mathbf{p}<$ & 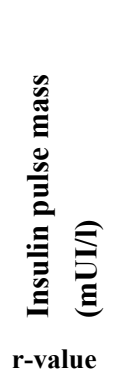 & $\mathbf{p}<$ \\
\hline $\begin{array}{l}\text { C-peptide } \\
(\mathrm{nmol} / \mathrm{l})\end{array}$ & 0.78 & 0.008 & 0.75 & 0.008 & 0.75 & 0.008 & & NS & & NS & & NS \\
\hline $\begin{array}{l}\text { HDL cholesterol } \\
(\mathrm{mmol} / \mathrm{l})\end{array}$ & -0.85 & 0.004 & -0.88 & 0.0007 & -0.89 & 0.0006 & & NS & & NS & & NS \\
\hline $\begin{array}{l}\text { Triglycerides } \\
(\mathrm{mmol} / \mathrm{l})\end{array}$ & 0.75 & 0.03 & 0.78 & 0.008 & 0.78 & 0.009 & & NS & & NS & & NS \\
\hline QUICKI & -0.77 & 0.002 & -0.99 & 0.0001 & -0.99 & 0.0001 & & NS & & NS & -0.59 & 0.03 \\
\hline $\begin{array}{l}\text { Prolactin } \\
(\mathrm{ng} / \mathrm{ml})\end{array}$ & & NS & & NS & & NS & 0.68 & 0.03 & 0.76 & 0.008 & & NS \\
\hline $\begin{array}{l}B M I \\
\left(\mathrm{~kg} / \mathrm{m}^{2}\right)\end{array}$ & & NS & & NS & & NS & 0.57 & 0.04 & & NS & & NS \\
\hline Cortisol (nmol/l) & & NS & & NS & & NS & & NS & 0.64 & 0.03 & & NS \\
\hline $\begin{array}{l}\text { Testosterone } \\
\text { (nmol/l) }\end{array}$ & & NS & & NS & & NS & & NS & & NS & 0.61 & 0.05 \\
\hline $\begin{array}{l}\text { SHBG } \\
(\text { nmol/l) }\end{array}$ & & NS & & NS & & NS & & NS & & NS & -0.88 & 0.0004 \\
\hline $\begin{array}{l}\text { DHEAS } \\
(\mathrm{nmol} / \mathrm{l})\end{array}$ & & NS & 0.73 & 0.02 & 0.73 & 0.02 & & NS & & NS & & NS \\
\hline
\end{tabular}

r-value-coefficient of correlation; p - value-statistical significance; NS - not significant; QUICKI - Quantitative insulin sensitivity check index; AUCO - 60 -area under the curve, overall insulin secretion per 60 minutes; ApEn - Approximate entropy; DHEAS dehydroepiandrosterone sulfate; SHBG - sex hormone binding globulin

Pulsatile insulin secretion results

Deconvolution analysis results are given in Table 2. Women affected with PCOS and healthy controls had similar average frequency of 10 insulin pulses per $60 \mathrm{~min}$. Variation in insulin burst frequency ranges from 6 to 13 insulin pulses per hour in both groups. We did not observe differences in number of insulin pulses, basal insulin secretion, pulse amplitude, pulse mass or in interpulse interval between the two groups. PCOS-affected women had broader insulin peaks in comparison to control group, as determined by the common-half pulse duration (1.97 (1.1-3.37) vs 0.89 (0.51-1.49) $\mathrm{mUI} / \mathrm{min} ; \mathrm{p}<0.07)$.

Basal insulin secretion correlated negatively with HDL-cholesterol ( $\mathrm{r}=-0.85$; $\mathrm{p}<0.004)$, QUICKI ( $\mathrm{r}=$ $-0.77 ; \mathrm{p}<0.002)$ and positively with triglycerides $(\mathrm{r}=$
0.75; $\mathrm{p}<0.03) . \quad \mathrm{AUC}_{0-60}$ correlated negatively with QUICKI ( $\mathrm{r}=-0.99 ; \mathrm{p}=0.0001)$, HDL-cholesterol ( $\mathrm{r}=$ $-0.89 ; \mathrm{p}<0.0006)$ and positively with triglycerides $(\mathrm{r}=$ 0.78; $<<0.009$ ) (Table 3.).

Insulin pulse amplitude $(\mathrm{r}=-0.61 ; \mathrm{p}<0.03)$ similarly as insulin pulse mass $(\mathrm{r}=-0.59 ; \mathrm{p}<0.03)$ correlated negatively with QUICKI. Common-half pulse duration correlated positively with prolactin $(\mathrm{r}=0.76$; $\mathrm{p}<0.008)$ and cortisol levels $(\mathrm{r}=0.64 ; \mathrm{p}<0.03)$. Burst mass correlated positively with testosterone $(\mathrm{r}=0.61$; $\mathrm{p}<0.05$ ) and negatively with SHBG levels ( $\mathrm{r}=-0.88$; $\mathrm{p}<0.0004$ ) (Table 3.).

\section{Insulin secretion regularity}

Insulin burst orderliness evaluated by ApEn did not differ significantly between women affected with 
PCOS and healthy subjects (1.14 (1.095-1.178) vs 1.079 (0.94-1.164), respectively; $\mathrm{p}<0.2)$. ApEn correlated positively with prolactin levels $(r=0.68 ; p<0.03)$ and with BMI $(r=0.57 ; \mathrm{p}<0.04)$.

\section{Discussion}

The present study was designed to assess the rapid insulin pulses, insulin secretion regularity and the potential factors affecting insulin pulsatile secretion in lean women affected with PCOS in comparison to healthy lean women. The main findings are as follows: 1. PCOS-affected women tended to have different insulin pulsatile secretion patterns described by the broader insulin pulses in comparison to healthy controls. 2. Steroid hormones and prolactin levels were related to different aspects of insulin pulsatile secretion.

We observed the tendency toward broader insulin peaks in PCOS, but no differences between PCOS and controls in number of insulin secretory events, insulin pulse amplitude, pulse mass, interpulse interval or insulin secretion orderliness. Many studies have shown alterations in insulin pulsatility and insulin release orderliness in different states connected with insulin resistance, such as in patients with diabetes mellitus type 2 (Porksen 1999), in first degree relatives of DM 2 patients (O'Rahilly et al. 1988), in obesity (Peiris et al 1992, Zarkovic et al. 2000) or in old people (Meneilly et al. 1999). Conversely, there are only few studies concerning insulin pulsatility in PCOS as in another states often connected with insulin resistance. In one of these studies, no significant difference in rapid fasting insulin pulse frequency, total insulin area or total pulse related area was found between PCOS and healthy controls (Armstrong et al. 2001).

We have found that higher prolactin levels were associated with more irregular insulin secretion as determined by higher ApEn and with different insulin secretory patterns. Prolactin could influence insulin secretion. In vitro, beta-cells of the pancreatic islets express prolactin receptors. Prolactin supports the growth of the pancreatic islets and stimulates insulin secretion (Ben-Jonathan et al. 2006). Prolactin could induce insulin resistance, as women with microprolactinomas were more insulin resistant than healthy women (Serri et al. 1986, Seki and Nagata 1991). Similarly hyperprolactinemic PCOS women were more insulin resistant than their normoprolactinemic counterparts (Bahceci et al. 2003).

We have also observed a positive correlation between insulin secretion regularity, as determined by ApEn values, and BMI. This finding is supported by other authors who have found an association of overweight and irregular insulin secretion with improvement after weight loss (Zarkovic et al. 2000).

Further, cortisol was positively correlated with the common half-duration of insulin peaks. Similarly to us, others shown that glucocorticoids could influence insulin secretion. Short-term glucocorticoid treatment impaired insulin pulsatility, probably by a disruption of the normal glucose-insulin feedback loop (Hollingdal et al. 2002).

Afterwards, we observed positive correlation of testosterone levels and negative correlation of SHBG and insulin pulse mass. Insulin increases the biological availability of testosterone through the suppression of SHBG synthesis. Hyperinsulinemia increases ovarian androgen production. Conversely, testosterone may indirectly contribute to insulin resistance throught facilitating free fatty acids release from abdominal fat and perhaps directly from muscular tissue reducing insulinmediated glucose uptake (Holte 1994, Holte et al. 1996, Cahová et al. 2007).

We used QUICKI to determine insulin sensitivity in PCOS-affected women and healthy controls. Both groups had the same insulin sensitivity. We observed a negative correlation between insulin sensitivity and basal insulin secretion. But we did not ascertain any correlation between insulin pulse frequency or interpulse interval and insulin sensitivity. Previously published results concerning the relationship between insulin sensitivity, measured by euglycaemic clamp, and insulin pulse frequency are, however, discrepant. One study concluded that the increased frequency of rapid insulin pulses might be related to the insulin resistance in patients with abdominal obesity. The number of rapid insulin pulses was reduced and insulin sensitivity was improved after weight loss (Peiris et al. 1992). On the other hand, insulin pulse frequency was not the indicator of insulin sensitivity in healthy subjects (Courtney et al. 2003) or women with polycystic ovary syndrome (Armstrong et al. 2001). These divergent results could be explained by different studied populations or by the use of varying approaches for assessment of insulin pulsatile secretion.

In conclusion, PCOS-affected women tended to have broader insulin peaks in comparison to healthy lean women. Prolactin, cortisol and androgens were related to some of the insulin pulsatile secretion characteristics, 
whereas parameteres describing insulin pulsatility were not significant determinants of insulin sensitivity.

\section{Conflict of Interest}

There is no conflict of interest.

\section{Acknowledgements}

This work was supported by grant MH CR NR 8759-3 and by the Albert Renold Fellowships of European Association for the Study of Diabetes (to Tereza Grimmichová). We thank Hana Zachystalová, Jana Novotná, Romana Bajtlová and Stanislava Štursová for excellent technical assistance.

\section{References}

AHREN B: Autonomic regulation of islet hormone secretion-implications for health and disease. Diabetologia 43: $393-$ 410, 2000.

ARMSTRONG VL, WIGGAM MI, ENNIS CN, SHERIDAN B, TRAUB AI, ATKINSON AB, BELL PM: Insulin action and insulin secretion in polycystic ovary syndrome treated with ethinyl oestradiol/cyproterone acetate. QJM 94: 31-37, 2001.

BAHCECI M, TUZCU A, BAHCECI S, TUZCU S: Is hyperprolactinemia associated with insulin resistance in nonobese patients with polycystic ovary syndrome? J Endocrinol Invest 26: 655-659, 2003.

BEN-JONATHAN N, HUGO ER, BRANDEBOURG TD, LAPENSEE CR: Focus on prolactin as a metabolic hormone. Trends Endocrinol Metab 17: 110-116, 2006.

CAHOVÁ M, VAVŘíNKOVÁ H, KAZDOVÁ L: Glucose-fatty acid interaction in skeletal muscle and adipose tissue in insulin resistance. Physiol Res 56: 1-15, 2007.

COURTNEY CH, ATKINSON AB, ENNIS CN, SHERIDAN B, BELL PM: Comparison of the priming effects of pulsatile and continuous insulin delivery on insulin action in man. Metabolism 52: 1050-1055, 2003.

EHRMANN DA, BARNES RB, ROSENFIELD RL, CAVAGHAN MK \& IMPERIAL: Prevalence of impaired glucose tolerance and diabetes in women with polycystic ovary syndrome. Diabetes Care 22: 141-146, 1999.

HOLLINGDAL M, JUHL CB, DALL R, STURIS J, VELDHUIS JD, SCHMITZ O, PORKSEN N: Glucocorticoid induced insulin resistance impairs basal but not glucose entrained high-frequency insulin pulsatility in humans. Diabetologia 45: 49-55, 2002.

HOLTE J: Disturbances in insulin secretion and sensitivity in women with the polycystic ovary syndrome. Baillieres Clin Endocrinol Metab 10: 221-247, 1996.

HOLTE J, BERGH T, BERNE C, BERGLUND L, LITHELL H: Enhanced early insulin response to glucose in relation to insulin resistance in women with polycystic ovary syndrome and normal glucose tolerance. $J$ Clin Endocrinol Metab 78: 1052-1058, 1994.

JOHNSON ML, VIROSTKO A, VELDHUIS JD, EVANS WS: Deconvolution analysis as a hormone pulse-detection algorithm. Methods Enzymol 384: 40-54, 2004.

KATZ A, NAMBI SS, MATHER K, BARON AD, FOLLMANN DA, SULLIVAN G, QUON MJ: Quantitative insulin sensitivity check index: a simple, accurate method for assessing insulin sensitivity in humans. $J$ Clin Endocrinol Metab 85: 2402-2410, 2000.

LEGRO RS, KUNSELMAN AR, DODSON WC, DUNAIF A: Prevalence and predictors of risk for type 2 diabetes mellitus and impaired glucose tolerance in polycystic ovary syndrome: a prospective, controlled study in 254 affected women. J Clin Endocrinol Metab 84: 165-169, 1999.

MENEILLY GS, VELDHUIS JD, ELAHI D: Disruption of the pulsatile and entropic modes of insulin release during an unvarying glucose stimulus in elderly individuals. J Clin Endocrinol Metab 84: 1938-1943, 1999.

O'MEARA NM, BLACKMAN JD, EHRMANN DA, BARNES RB, JASPAN JB, ROSENFIELD RL, POLONSKY KS: Defects in beta-cell function in functional ovarian hyperandrogenism. J Clin Endocrinol Metab 76: 1241$1247,1993$.

O'RAHILLY S, TURNER RC, MATTHEWS DR: Impaired pulsatile secretion of insulin in relatives of patients with non-insulin-dependent diabetes. N Engl J Med 318: 1225-1230, 1988.

PEIRIS AN, STAGNER JI, VOGEL RL, NAKAGAWA A, SAMOLS E: Body fat distribution and peripheral insulin sensitivity in healthy men: role of insulin pulsatility. J Clin Endocrinol Metab 75: 290-294, 1992.

PINCUS SM, HARTMAN ML, ROELFSEMA F, THORNER MO, VELDHUIS JD: Hormone pulsatility discrimination via coarse and short time sampling. Am J Physiol 277: E948-E957, 1999.

PORKSEN N: Early changes in the function of pancreatic beta cells and insulin pulsatility as predictors of type 2 diabetes. Diabetes Metab 25: 14-16, 1999.

PORKSEN N: The in vivo regulation of pulsatile insulin secretion. Diabetologia 45: 3-20, 2002. 
PORKSEN N, MUNN S, STEERS J, VORE S, VELDHUIS J, BUTLER P: Pulsatile insulin secretion accounts for $70 \%$ of total insulin secretion during fasting. Am J Physiol 269: E478-E488, 1995.

PORKSEN N, JUHL C, HOLLINGDAL M, PINCUS SM, STURIS J, VELDHUIS JD, SCHMITZ O: Concordant induction of rapid in vivo pulsatile insulin secretion by recurrent punctuated glucose infusions. Am J Physiol 278: E162-E170, 2000.

ROTTERDAM ESHRE/ASRM-SPONSORED PCOS CONSENSUS WORKSHOP GROUP: Revised 2003 consensus on diagnostic criteria and long-term health risks related to polycystic ovary syndrome. Fertil Steril 81: 19-25, 2004.

SEKI K, NAGATA I: Levels of glucose and insulin during twenty-four hours in hyperprolactinemic women with pituitary microadenoma. Gynecol Obstet Invest 31: 222-225, 1991.

SERRI O, BEAUREGARD H, RASIO E, HARDY J: Decreased sensitivity to insulin in women with microprolactinomas. Fertil Steril 45: 572-574, 1986.

STAGNER JI, SAMOLS E, WEIR GC: Sustained oscillations of insulin, glucagon, and somatostatin from the isolated canine pancreas during exposure to a constant glucose concentration. J Clin Invest 65: 939-942, 1980.

VELDHUIS JD, JOHNSON ML: Deconvolution analysis of hormone data. Methods Enzymol 210: 539-575, 1992.

VELDHUIS JD, JOHNSON ML: Analytical methods for evaluating episodic secretory activity within neuroendocrine axes. Neurosci Biobehav Rev 18: 605-612, 1994.

VRBÍKOVÁ J, GRIMMICHOVÁ T, DVOŘÁKOVÁ K, HILL M, STANICKÁ S, VONDRA K: Family history of diabetes mellitus determines insulin sensitivity and beta cell function in polycystic ovary syndrome. Physiol Res, Jul 26, 2007 (Epub ahead of print).

ZARKOVIC M, CIRIC J, PENEZIC Z, TRBOJEVIC B, DREZGIC M: Effect of weight loss on the pulsatile insulin secretion. J Clin Endocrinol Metab 85: 3673-3677, 2000. 